\title{
Efficacy of Rational Emotive Therapy in the Management of Antisocial Personality Disorder among Adolescents in Owerri Municipal, Imo State, Nigeria
}

\author{
Dr. Chikwe Agbakwuru \\ Department Of Educational Psychology, Guidance and Counselling. \\ University of Port Harcourt, Rivers State, Nigeria \\ Dr. Hope Ejiociii Mgbeoduru \\ Holy Rosary International College, \\ Owerri, Imo State, Nigeria.
}

\begin{abstract}
This study investigated the efficacy of Rational Emotive Therapy in, the management of (ASPD) among adolescents in Owerri municipal, Imo State, Nigeria. It adopted a quasiexperimental design of pre-test post-test control group. Three research questions and three hypotheses tested at 0.05 level of significance guided the study. Thirty adolescents who were eighteen years formed the sample. Mean, standard derivation, $t$ test and 2 ways ANOVA were used to analyze the data obtained. The results obtained showed that Rational Emotive Therapy is efficacious in the management of antisocial personality disorder at post and follow up tests. The results also indicate that male and female adolescents have ASPD and are amenable to change using cognitive restructuring technique of Rational Emotive Therapy. Based on the findings, it was recommended that counselling psychologists should be posted to schools and made teaching subject free to enable them identify and work on adolescents with ASPD and its antecedents of Attention Deficit Hyperactivity Disorder, Oppositional Defiant Disorder and Conduct Disorders.
\end{abstract}

Keywords: Antisocial, Personality Disorder, Rational Emotive Therapy.

\section{INTRODUCTION}

Instances abound in the manifestation of antisocial personality disorder as a pervasive and persistent disregard for morals, social norms, the rights and feelings of others. Every person's personality is unique. However in some cases, a person's way of thinking and behaving can be destructive both to others and to the person himself or herself. Antisocial personality disorder is a mental health condition in which a person has a long term pattern of manipulating, exploiting or violating the rights of others.

According to Bressert (2016), antisocial personality disorder is characterized by a long standing pattern of disregard for other people's rights, often crossing the line and violating those rights. A person with ASPD often feels little or no empathy toward other people and does not see the problem in bending or breaking the law for their own needs or wants. They tend to be callous, cynical and contemptuous of the feelings, rights and sufferings of others. They may have an inflated and arrogant self-appraisal, for example, feel that ordinary work is beneath them or lack a realistic concern about their current problems or their future and may be excessively opinionated, self-assured or cocky. Antisocial personality disorder according to American Psychiatric Association (2013) is diagnosed when a person's pattern of antisocial behaviour has occurred since fifteen years although only adults of eighteen years and above 
can be diagnosed with this disorder. It consists of the majority of these symptoms: exploiting, manipulating or violating the right of others, lack of concern, regret or remorse about other peoples' distress; behaving irresponsibly and showing disregard for normal social behaviours; having difficulty in sustaining long term relationship; being unable to control one's anger; lack of quit or not learning from their mistakes; blaming others for problems in their lives; and repeatedly breaking the law.

Hagan (2010) citing Farrington found out that individuals with antisocial personality disorder often and divorced, abuse alcohol/drugs, are anxious, depressed, unemployed, homelessness and exhibit criminal behaviours. However, some individuals with this disorder rise to high positions of power in society by becoming masters of manipulation and deceit.

In Mayo Clinic (2016), Antisocial Personality Disorder is put in the cluster B of personality disorder and described as disregard for other's needs or feelings, persistent lying, stealing, using aliases, conning others, recurring problems with the law, repeated violation of the rights of others, aggressive, often violent behaviours; disregard for the safety of self and others, impulsive behaviour, and consistent irresponsible lack of remorse for behaviour.

The American Psychiatric Association (2000) defines antisocial personality disorder cluster B as: a pervasive pattern of disregard for and violation of the rights of others occurring since age fifteen years as indicated by three or more of the following: failure to confirm to social norms with respect to lawful behaviours as indicated by repeatedly performing acts that are grounds for arrest; deception as indicated by repeatedly lying, use of aliases or concerning others for personal profit or pleasure, impulsivity or failure to plan ahead; irritability and aggressiveness as indicated by repeated physical fights or assaults; reckless disregard for safety of self or others; consistent irresponsibility as indicated by repeated failure to sustain consistent work behaviour or honour financial obligations; lack of remorse as indicated by being indifferent to or rationalizing having hurt, mistreated or stolen from another.

According to the National Institute for Health and Care Excellence (NICE, 2015) antisocial personality disorder is characterized by a diminished capacity for remorse and poor behavioural controls. They are dauntless, venture some, intrepid, bold, audacious, daring, reckless, fools, hardy, impulsive, heedless, unbalanced by hazard, and pursues perilous ventures. These individuals are easily bored and seek activities that will excite 'them. They could be brutal assaults, murderes, sky diving pranks, doing dares and putting one's life at risk. The violent activities such as murder and assault are not necessarily sadistic in nature but more of a rash or thrill for the perpetrator. They are reckless and bold individuals who have no regard for their own safety or the safety of others. People with antisocial personality disorder exhibit traits of impulsivity, high negative emotionality, low conscientiousness and associated behaviours including irresponsible and exploitative behaviour, recklessness and deceitfulness. Continuing, NICE indicates that people with ASPD present unstable interpersonal relationships, disregard for the consequences of their behaviours, a failure to learn from experience, egocentricity, a disregard for the feelings of others, a wide range of interpersonal and social disturbances, counorbid depression, anxiety, alcohol and drug misuse. The key features of antisocial personality disorder are impairment in the ability to form positive relationship with others and a tendency to engage in behaviours that violate basic social norms and values. People with this disorder are cold and callous, gaining pleasures by compelling with and initiating everyone and any one. They can be cruel and malicious, commit violent criminal offenses against others including assault, murder and rape much more frequently than do people without the disorder. Millon (2000) observes that ASPD often insists on being seen as falters and are dogmatic in their opinions. However, when they need to, people with ASPD can 
act gracious and cheerful until they get what they want. They then may revert to being brash and arrogant. A prominent characteristic of ASPD is poor control of impulses. People with this disorder have a low tolerance for frustration and often act impetuously with no apparent concern for the consequences of their behaviours. They often take chances and seek thrills with no concern for change. They are easily bored and restless, unable to endure the tedium of routine or to persist at the day-to-day responsibilities of marriage or a job. Continuing Millon said that ASPD is characterized by a pervasive pattern of disregard for or violation of the rights of others, an impoverished moral sense or conscience is often apparent as well as a history of crime, legal problems and or impulsive and aggressive behaviour. They tend to drift from one relationship to another or often are in lower status jobs and low level of education. The individuals must be at least eighteen years. In childhood, these individuals usually have oppositional defiant disorder towards parents and teachers which develop into conduct disorder (Delinquency) in adolescence.

In adulthood, individuals with ASPD become more antagonistic. They show an exaggerated sense of self-importance, insensitivity towards the feelings and needs of others and callous exploitation of others. Their increase manipulation, callousness, deceitfulness and hostility repeatedly put them at odds with other people.

Antisocial personality Disorder tends to 'act out' tensions and problems rather than worry them out. Their apparent lack of anxiety and guilt combined with the appearances of sincerity and candor may enable them to avoid suspicion and detection for stealing and illegal activities. They often show contempt for those they are able to take advantage of the 'marks'.

Antisocial personalities are irresponsible and impulsive in behaviour, as well as low frustration tolerance. They generally have a callous disregard for the rights, needs and wellbeing of others. They are typically chronic liars and have learned to take rather than earn what they want. They are prone to thrill-seeking and deviant and unconventional behaviours, they often break the law impulsively and without regard for the consequences. They seldom forgo immediate pleasure for future gains and long range goals. They live in the present without realistically considering either past or future. External reality is used for immediate personal gratification. They are unable to endure routine or to shoulder responsibility, they frequently change jobs. Antisocial personalities have the ability to put up "a good front" to impress and exploit others, projecting blame onto others for their own socially disproved behaviour. According to Black (2016) antisocial personality disorder is exhibited through rejection of authority and inability to profit from experience. Antisocial individuals behave as if social regulations do not apply to them. Frequently they have a history of difficulties with educational and law enforcement authorities. Yet, although they often drift into criminal activities, they are not typically calculating professional criminals. Despite the difficulties they get into and the punishment they may receive, they go on behaving as if they will be immune from the consequences of their actions. Black (2016) indicates that antisocial personalities are unable to maintain good interpersonal relationships. Although initially they are able to win the liking and friendship of other people, they are seldom able to keep close friends. Irresponsible and egocentric, they are usually cynical, unsympathetic, ungrateful and remorseless in their dealings. They seemingly cannot understand love in others or give it in return. Continuing Black (2016) said that the antisocial personality disordered individuals are unconscientiously careless, irresponsible and disorderly people, frivolous and undependable. They lack clear life goals and the motivation to pursue them. They also lack the essential social skill of respect, responsibility and honesty. They equally lack co-operation, generosity, kindness, chastity, caution, and control of anger. 
In related way, the American Psychiatric Association (2013) in their own diagnosis identified the following as characteristics of Antisocial Personality Disorder: failure to conform to social norms, deceitfulness impulsivity, irritability and aggressiveness, lack of remorse, consistent irresponsibility, reckless disregard for safety of self and others, indifference to the welfare of others and failure to plan ahead.

Moffitt and Caspi (2001) compared childhood risk factors of male and female adolescents portraying childhood onset and adolescent onset antisocial personality behaviour which influences deviant behaviour in individuals. This study showed a male-to-female ratio of 10:1 for those experiencing childhood onset delinquency and 15:1 for adolescent onset delinquency. Moffitt and Caspi (2001) hypothesized that life-course-persistent antisocial behaviour originates early in life, when the difficult behaviour of a high-risk young child is exacerbated by a high risk-social environment.

Nowadays, many adolescents engage in behaviours and activities that are criminal and reasons for arrest. There are reports in the facebook, daily newspapers,, magazines and daily occurrences within the neighborhood of adolescents who are manifesting increased violence, disorderliness, drunkenness, disrespect for constituted authorities, abuse of other people's rights, sheer recklessness, armed robbery, harassment, intimidation, truancy, school dropout, kidnapping, raping, killings and many more. It is painful that our young ones, some as young as thirteen years old are involved in the vices. It is believed they could be helped using the cognitive restructuring techniques Of Rational Emotive Therapy to treat their antisocial personality disorder at the post-follow up stages of treatment.

Albert Ellis was the proponent of Rational Emotive Therapy. His basic idea about the nature of man is that man is inherently both rational and irrational in his belief system and-the type of belief held at any point in time about events and circumstances in his environment influence his emotions and behaviour. RET concentrates primarily on the superego concept of psychoanalysis. By a forceful attack on the client superego, Elis attempts to get him to change his values particularly in regard to sexuality and accordingly to change his behaviour.

Citing Ellis, Reuben (1978) said that man is born with a potential to be uniquely rational and straight thinking as well as a tendency to be $a_{n}$ uniquely irrational and crooked thinking creature. He has powerful predispositions to be self-preserving and pleasure-producing including the predispositions to think, to use language, to think about his thinking, to be creative, to be sensuous and sexual, to love, to be interested in his fellows, to organize, to learn by his mistakes and to actualize some of his potentials for life and growth. On the other hand, he also has optionally potent propensities to be self-destructive, to be a short-range hedonist, to avoid thinking things through, to shirk responsibilities, to procrastinate, to hate, to be callous, to make the same mistakes endlessly, to be superstitious, to be intolerant and dogmatic, to be perfectionistic and grandiose, and to avoid actualizing his potentials for growth. RET holds that virtually all serious emotional problems with which humans are beset directly stem from their magical, superstitious, empirically unvalidated thinking and that if disturbances creating ideas are vigorously and persistently disputed by a vigorous application of the principles of logico-empirical thinking, they can almost invariably be eliminated and will ultimately cease to reoccur. Ellis states that no matter how defective an individual's heredity may have been and no matter what traumatic experience he may have been subjected to during, his early or latter life, the main reason why he is now over-reacting or under-reacting to obnoxious stimuli at point A that is (Activating Event) is because he now has some dogmatic, irrational, unexamined belief at point B that is (Belief). Because these beliefs are not related to reality, they will not withstand objective scrutiny. They are essentially deifications and/or 
devilifications of himself or others, and when empirically checked and logically assailed, they tend to evaporate. If it is forced forward lead to point $\mathrm{C}$ that is (consequence). Rational emotive psychology asserts that ordinary psychological insight does not lead to major personality change, since at best it only helps the individual to see that he does have an emotional problem and that this problem has antecedent presumably in the experience that occurred during his childhood. According to RET theory, this kind of insight is largely misleading for as noted earlier on, it is not the activating Event (A) of the individuals' prior life that cause his dysfunctional emotional consequence (C), it is much more importantly his (in bom and acquired) tendency to interpret these events unrealistically and therefore to have irrational beliefs (B) about them. The real cause of his emotional upsets therefore is himself and not what happens to him (even though the experiences in his life obviously have some influence over what he thinks and feels). In RET, insight A-the person's self- defeating behaviour is related to antecedent and understandable cause is duly stressed, but he is led to see these antecedents largely in terms of this own beliefs and not in terms of past or present activating events. Insight B. is the understanding that although he became emotionally disturbed (or more accurately, made himself disturbed) in the past, he is now upset because he keeps indoctrinating himself with the same kind of magical beliefs. He is still here and now actively reinforcing them by his contemporary mixed-up thinking and. foolish actions or inactions, and it is his own present active self propandizations that truly keep them alive. Unless he fully admits and faces his own responsibility and culpability for the continuation of these irrational beliefs, it is unlikely that he will try to uproot them.

Insight C- is the client's clearly and vehemently acknowledging that since it is his or her own tendency to think crookedly that created his emotional malfunctioning in the first place, and that since it is his own continuous re-indoctrinations and habituations that keep this magical thinking extent in the second place, nothing short of hardwork and practice will probably correct those irrational beliefs and keep them corrected. Only repeated rethinking in regard to his irrational beliefs and repeated actions designed to undo them are likely to extinguish or minimize them.

In the opinion of the researchers, Rational Emotive Therapy assess behaviours in accordance with preceding events which are strengthened positively or negatively by the belief system resulting in actions and reaction. Rational Emotive Therapy is a cognitive restructuring technique (CRT). In a study, Kumar, (2009) examined the impact of Rational Emotive Behaviour Therapy (REBT) on adolescent students with conduct disorder (CD). It was hypothesized that the REBT would have a positive impact on adolescents conduct disorder symptoms. The youth Self-Report (YSR) was distributed to 1142 students and they were instructed to fill the forms. The sample included 200 students (100 girls, 100 boys) which 100 was taken as control group (50 girls, 50 boys) and the other 100 was taken for experimental group (50 girls and 50 boys) from the schools and colleges in Mysore. The intervention programme was given on experimental groups for seven sessions in seven weeks. There were 10 groups with 10 subjects in each group. The intervention programme consisted of cognitive, emotive and behavioural techniques of REBT. Subjects were taught the techniques of REBT and how to apply it on their problems. One month later the last intervention programme and the post test were given to assess the impact of REBT. Data 'analysis involved the use of repeated measure of ANOVA to measure the impact of REBT on CD symptoms of subjects. Significant impacts were found on the reduction of CD symptoms experienced by subjects. The results revealed that the treatment decreased the symptoms of CD. The results showed that REBT has a positive impact on $C D$ and other emotional and behaviour disorders comorbid with CD experienced by adolescents. 
In the light of the finding of Kumar (2009), this study was embarked on to find out the efficacy of Rational Emotive Therapy in the management of Antisocial Personality Disorder among adolescents in Owerri Municipal, Imo State, Nigeria. The study was guided by the following research questions:

1. How efficacious is cognitive restructuring technique of Rational Emotive Therapy in the management of antisocial personality disorder of adolescents?

2. What difference exists in the ASPD mean scores of the adolescents in Rational Emotive Therapy and control group based on gender at post test?

3. To what extent do the mean scores on ASPD of adolescents in the Rational Emotive Therapy and control group differ at follow up test based on gender?

Similarly, the following hypotheses were formulated to guard the study:

Ho1: The efficacy of cognitive restructuring technique of Rational Emotive Therapy in the management of antisocial personality disorder of adolescents at post - test is not significant.

Ho2: There is no significant ASPD mean score difference among the adolescents in Rational Emotive Therapy and control group based on gender at post test.

Ho $_{3}$ : The follow up mean scores on ASPD of the adolescents in the Rational Emotive Therapy and control group do not differ significantly based on gender.

\section{METHODOLOGY}

The study used the quasi-experimental pre-test - post-test-control group design comprising of one group - the experimental group of rational emotive therapy technique while the control group received a placebo on marriage. This type of design-required that the subjects be tested with the same instrument before and after treatment. The researchers determined the effects of treatment by comparing the results of the subjects in,-the treatment group with the control group.

The participants in this study consisted of adolescents who were eighteen years in the Senior Secondary three (SS3). They were given Adolescents Interaction Admission Form in which they indicated their ages, classes and sex. They were further given the Adolescent Antisocial Personality Inventory to respond to. Those who scored fifty percent and above were taken as having antisocial personality disorder. They comprised of seventeen adolescents in the treatment group and control group thirteen making a total of thirty participants of fourteen males and sixteen females.

A researchers developed instrument - Adolescent .Antisocial Personality Disorder Inventory was used to collect relevant data at pre - post and follow up stages. It was a 49 - item Inventory developed from the seven categories of antisocial personality disorder traits. It was scored on a three point format of always, sometimes and rarely. The instrument was validated at the face and content levels by experts in measurement and evaluation and tested with Cronbach Alpha which established 0.77 as its reliability coefficient.

The study was carried out over a period of five weeks. Treatment sessions were held for the experimental group for one hour twice a week for ten sessions. The seven categories of antisocial personality disorder of non-conformity to social norms, deception, aggressiveness and irritability, lack of remorse, impulsivity, consistent irresponsibility and lack of regard for the safety of self and others were treated using rational emotive therapy. This technique involves giving the subjects a point of view different from their own so that they can see themselves and their behaviours as others view them. It is a way the therapist honestly and without fear or favour points out to the client the disruptive way he is behaving, the way other people see such behaviours and the client himself and the need to behave in desirable 
manners. So the training sessions focused on series of expository lectures, group discussions and take home assignments. There was deep interaction between the- researchers and the participants throughout the treatment period. The follow-up stage of the experiment was carried out four weeks after treatment using Adolescent Antisocial personality Disorder Inventory reshuffled to find out the degree of permanence of the treatment gains on the adolescents.

The data obtained in this study were statistically analyzed to determine the effectiveness of the experimental treatment of Rational Emotive Therapy to manage antisocial personality disorder. Mean statistic and standard deviation were used to answer the research questions while paired t-test was used to test hypothesis 1 and 2 - way ANOVA was used to test hypotheses 2 and 3 at the significant level of $0.05(\mathrm{P}<0.05)$.

\section{RESULTS}

Results of statistical analysis of data are presented in the following tables:

Research Question 1: How efficacious is cognitive restructuring technique of Rational Emotive Therapy in the management of ASPD among adolescents?

Hypothesis 1: The efficacy of the cognitive restructuring technique of Rational Emotive Therapy in the management of ASPD among adolescents is not significant.

To answer research question 1, the mean and standard deviation of the adolescents in Rational Emotive Therapy group were computed at the pre and post test level. The mean difference obtained from the pretest to the post test was subjected to paired t-test statistics to determine its significance. The results obtained were summarized and displayed in table 1.

Table 1: Mean, standard deviation and paired t-test on the efficacy of RET in the management of ASPD

\begin{tabular}{|l|c|c|c|c|c|c|c|}
\hline \multicolumn{1}{|c|}{ Test } & N & Means & SD & $\begin{array}{c}\text { Reduced } \\
\text { Mean }\end{array}$ & DF & t-value & P-valve \\
\hline $\begin{array}{l}\text { Pre test } \\
\text { Post test }\end{array}$ & 22 & 64.36 & 3.98 & 22.04 & 21 & 25.66 & 0.000 \\
\hline
\end{tabular}

In table 1, it is shown that the adolescents in the Rational Emotive Therapy group had the mean scores of $64.36(\mathrm{SD}=3.98)$ and $42.32(\mathrm{SD}=3.46)$ respectively in their pre and post tests. Based on these mean scores, it is clear that from the pretest to the post test level, the adolescents in the Rational Emotive Therapy group lost a mean score of 22.04.

Table 1 also shows that when the observed mean difference was subjected to a paired t- test statistics, a calculated t-value of 25.66 was obtained at df 21 and 0.0005 level of significance. So the null hypothesis is rejected since the obtained significance level of 0.0005 is less than the chosen alpha level of 0.05. This indicated that Rational Emotive Therapy is significantly efficacious in the management of ASPD among adolescents.

Research Question 2: What difference exist in the ASPD mean score of adolescent in Rational Emotive Therapy and control group based on gender at post-test.

Hypothesis 2: There is no significant ASPD mean score difference among adolescent in Rational Emotive Therapy and control group based on gender at post-test. 
Table 2: Mean, standard deviation and 2- way ANOVA on the mean score differences of adolescents in Rational Emotive Therapy and control group in the management of ASPD among adolescents at post test.

\begin{tabular}{|l|l|c|c|c|}
\hline \multicolumn{1}{|c|}{ Groups } & Gender & N & Means & $\begin{array}{c}\text { Standard } \\
\text { Deviation }\end{array}$ \\
\hline Rational Emotive Therapy & Female & 9 & 41.22 & 3.19 \\
& Male & 13 & 43.08 & 3.54 \\
& Total & 22 & 42.32 & 3.45 \\
\hline Control & Female & 8 & 64.00 & 3.46 \\
& Male & 5 & 63.00 & 2.34 \\
& Total & 13 & 62.62 & 3.01 \\
\hline Total & Female & 17 & 51.94 & 12.153 \\
& Male & 18 & 48.61 & 9.72 \\
& Total & 35 & 50.23 & 10.93 \\
\hline
\end{tabular}

Test of between subject effects (2-way ANOVA)

\begin{tabular}{|c|c|c|c|c|c|c|}
\hline Source & $\begin{array}{l}\text { Type III sum of } \\
\text { square }\end{array}$ & df & Mean sq & $\mathbf{F}$ & Sig & Result \\
\hline Corrected model & 3727.693 & 3 & 1242.564 & 113.802 & 0.000 & Significant \\
\hline Intercept & 87026.030 & 1 & 87026.030 & 9970.391 & 0.000 & Significant \\
\hline Groups & 3554.077 & 1 & 3554.077 & 325.505 & 0.000 & Significant \\
\hline Gender & 1.424 & 1 & 1.424 & 0.130 & 0.720 & Insignificant \\
\hline Groups \& Gender & 15.885 & 1 & 15.885 & 1.455 & 0.237 & Insignificant \\
\hline Error & 338.479 & 31 & 10.919 & & & \\
\hline Total & 92368.000 & 35 & & & & \\
\hline Corrected Total & 4066.171 & 34 & & & & \\
\hline
\end{tabular}

Table 2 shows that the females have a mean of 41.22 and males a mean of 43.08 with SD of 3.19 and 3.54 respectively for the RET. In the control group, the females have a mean of 64.00 and 63.00 for males with SD of 3.46'and 2.34 respectively. The total mean value for both experimental group (RET) and control group is 42.32 and 62.62 respectively. So from their mean values, the mean difference is 20.30. Furthermore, the test of between subject effect shows intercept 87026.030 and 3554.077 for groups. The significance values for intercept is 0 000 and interaction 0.000 . Since significance $(P=0.000<0.05)$, the null hypothesis is rejected to retain the alternate that there is significant ASDP mean score difference among adolescent's in treatment group (RET) and control group based on gender at post-test.

Research Question 3: To what extent do the mean scores on ASPD of adolescents in Rational Emotive Therapy and control group differ at follow-up of test based on gender?

Hypotheses 3: The follow up mean scores on ASPD of adolescent in Rational Emotive Therapy and control group do not differ significantly based on gender. 
Table 3: Mean, standard deviation and 2- way ANOVA on the mean scores difference of adolescents in Rational Emotive Therapy and control group in the management of ASPD among adolescents at follow up test.

\begin{tabular}{|l|l|c|c|c|}
\hline \multicolumn{1}{|c|}{ Groups } & Gender & N & Means & $\begin{array}{c}\text { Standard } \\
\text { Deviation }\end{array}$ \\
\hline Rational Emotive Therapy & Female & 9 & 36.33 & 5.50 \\
& Male & 13 & 37.54 & 4.82 \\
& Total & 22 & 37.05 & 4.84 \\
\hline Control & Female & 8 & 62.50 & 1.77 \\
& Male & 5 & 62.80 & 3.03 \\
& Total & 13 & 62.62 & 2.22 \\
\hline Total & Female & 17 & 48.65 & 13.98 \\
& Male & 18 & 44.56 & 12.42 \\
& Total & 35 & 46.56 & 13.17 \\
\hline
\end{tabular}

Tests of between subjects effects (2- way ANOVA)

\begin{tabular}{|c|c|c|c|c|c|c|}
\hline Source & $\begin{array}{l}\text { Type III Sum } \\
\text { of Squares }\end{array}$ & df & Mean Square & $\mathbf{F}$ & Sig & Result \\
\hline Corrected Model & 5350.655 & 3. & 1783.552 & 102.005 & .000 & Significant \\
\hline Intercept & 77323.120 & 1 & 77323.10 & 4422.289 & .000 & Significant \\
\hline Groups & 5155.329 & 1 & 5155.329 & 294.845 & .000 & Significant \\
\hline Gender & 4.416 & 1 & 4.416 & .253 & 619 & Insignificant \\
\hline Groups and Gender & 15.597 & 1 & 1.597 & .019 & .765 & Insignificant \\
\hline Error & 542.031 & 31 & 17.485 & & & \\
\hline Total & 31711.000. & 35 & & & & \\
\hline Corrected Total & 5892.686 & 34 & & & & \\
\hline
\end{tabular}

In table 3 female and male adolescents in RET have 36.33 and 37.54 mean scores and SD of 5.05 and 4.82 respectively. The control group means show females have 62.50 males 62.80 and SD female 1.77 and males 3.03 respectively. Both the experimental and control groups have a total mean score of 37.05 and 62.62 and therefore a mean difference of 25.57. In addition, the test between subject effects indicates that intercept is 77323.120 and interaction 5155.329. Significant values for intercept is $\mathbf{. 0 0 0}$ and interaction $\mathbf{. 0 0 0}$. Now that significant value (P$0.000<.0 .05$ ) the null hypotheses is rejected and that means that there is significant ASPD mean score difference among adolescents in the treatment group (RET) and control group based on gender at follow up.

\section{DISCUSSION}

The findings of the study show that Rational Emotive Therapy is efficacious in the management of ASPD among adolescents. This is indicated in the reduction in the mean scores of the subjects in the treatment group and the control group as 25.57. To confirm the significance of the efficacy of Rational Emotive Therapy in the management of ASPD, the 2-way ANOVA yielded a p-value less than $t$-value in which the null hypothesis is rejected to accept that there is a significant difference between the experimental group and the control group. Rational Emotive Therapy has not been used as a singular treatment technique in this study but as cognitive restructuring technique. When Kumar (2009) examined the impact of REBT on adolescents with conduct disorder, the result revealed that the treatment decreased the symptoms of CD. The result showed that REBT has a positive impact on CD and other emotional and behavioural disorders. Males and females are open to ASPD and both are 
receptive to treatment and change, males seem to have more reduction then females though the differences might be insignificant. This might be as a result of the consciousness in the males that they are more prone to ASPD and other behaviour problems and so may have been more open to treatment.

For this study, the effectiveness of rational emotive therapy was achieved as the researchers applied the procedure of RET of addressing activating events, belief systems and consequences to achieve good results. Adolescents are immature, have incomplete socialization and easily form shabby opinions about life, choices and styles.

\section{CONCLUSION}

The findings of this study have proved that adolescents with ASPD can be managed or treated. Hence there is need to build in the traits of ASPD and the management skills in school curriculum to encourage detailed information and knowledge which are correct and factual. This will help to curb early onset of ASPD which starts early in children from attention deficit hyperactivity disorder to oppositional defiant disorder to conduct disorder and to antisocial personality disorder.

\section{RECOMMENDATIONS}

In the light of the results of this study, the following recommendations are hereby made:

- Parents should observe their children closely to detect early onset of antisocial personality disorder as they manifest attention deficit hyperactivity disorder, oppositional defiant disorder and conduct disorder.

- There should be counselling psychologists in the schools from primary to higher levels.

- These counselling psychologists should be subject teaching free to enable them devote more time to dictating and counselling students with behavioural and personality disorders.

- The curricular should be challenging and providing varieties so that adolescents thrilling tendencies can be captured and redirected.

- Parents should provide enabling environment in which children can develop positive personality.

- This research work should be carried out at intervals to see the permanency of result of treatment and should be extended to other locations for adolescents there.

\section{References}

American Psychiatric Association (2000). Diagnostic manual mental disorder (4th edition).

American Psychiatric Association (2013). Diagnostic manual of mental disorder (5 th $^{\text {edition). }}$

Black, D.W. (2016). Antisocial personality disorder: Epidemiology clinical manifestations, course and diagnosis http://www.update.com/hane. Accessed March 21, 2016.

Bressert, S. (2016). Antissocial personality disorder. Psychcentral. Retrieved on Feb. 9, 2017 from https://psycentral.com/disorders/antisocialpersonality-disorders-symptoms/

Hagan, F-E. (2010). Introduction to criminology: theories, methods and criminal books. Goggle.com.ng, https://books. Goggle.com.ng/books?

Kumar, G.V. (2009). Impact of RET on adolescent with CD. Journal of the Indicate Academy of Applied Psychology. $35,103-11$.

Mayo Clinic Staff (April, 2, 2016). “Overview” antisocial personality disorder. Mayo Foundation for Medical Education and Research.

Millon, T. (2000). Personality disorder in modern life (2ud edition). Hoboken, New Jersey: John Wiley \& Sons Inc.

Moffitt, T. \& Caspi, A. (2001). Childhood predictors differentiate life-course persistent and adolescence limited antisocial pathways among males and females. Development and Psychopathology, 355-375. 
National Institute for Health and Care Excellence (NICE) (2015).

Rueben, F. (1978). Psychoanalysis. In R. Corsini (Ed). Current psychotherapies. Itasca, Illinosis: F.E. Peacock Publishers Inc. 